\title{
Study of The Correlation Between World Patenting Trends and The University Admission Rate in Russia Based on Open Data
}

\author{
Igor Balk ${ }^{*}$, Elena Tishchenko, Natalia Ivashchenko ${ }^{1}$ \\ ${ }^{1}$ Lomonosov Moscow State University
}

\begin{abstract}
This paper discusses use of the open PCT patent data and university admission rate to study world technological trends and correlation between industry trends and the student admission rate for government sponsored University programs in Russia. OECD open statistical database and Lomonosov Moscow State University open admission data is used as a data source in this study. ICT and biotechnology industries used as a sample industries to study this correlations.
\end{abstract}

Keywords: open data, ITC, biotechnology, patent trends, admission rate, government scholarship in Russia

\section{Patens as a data source of the technological trends monitoring}

It is well know that number of issued patent can be used as economic indicator to monitor industry trends. According to the study conducted by NSF on the Science Indicators and Engineering in 2012, it is possible to show relationship between the number of conducted research works and the number of patents filed (the country's leaders are the same). [1] At the same time, according to the World Patent Organization, there is a definite correlation between the number of patents registered in the territory of the country and its gross domestic product (GDP). So Russia from 1997 to 2011 doubled its GDP, at the same time doubled and the number of registered patents (see. Figure 1-3) [2].

In the study "Using patent data for technology analyses and planning" Mary Ellen Mogee notes that patents have several advantages as a "technology indicator" [3]. It is important to note that the average ratio between the number of patents and the number of jobs in the computer manufacturing industry is 55.5 patents per year for 1,000 jobs in the chemical industry is already 16 patents per year for 1,000 jobs in the production of plastic 10, 2 patents for $1,000 \mathrm{jobs}$, and in the food industry 0.1 patents per year for $1,000 \mathrm{jobs}$. On average in the US economy 1,000 jobs produces 25.5 patent for 5 years or 5.1 patents per year [4].

\footnotetext{
*Corresponding author email info@innoationlabs.net
} 
IP Filings and Economic Growth (Set first available year to 1)

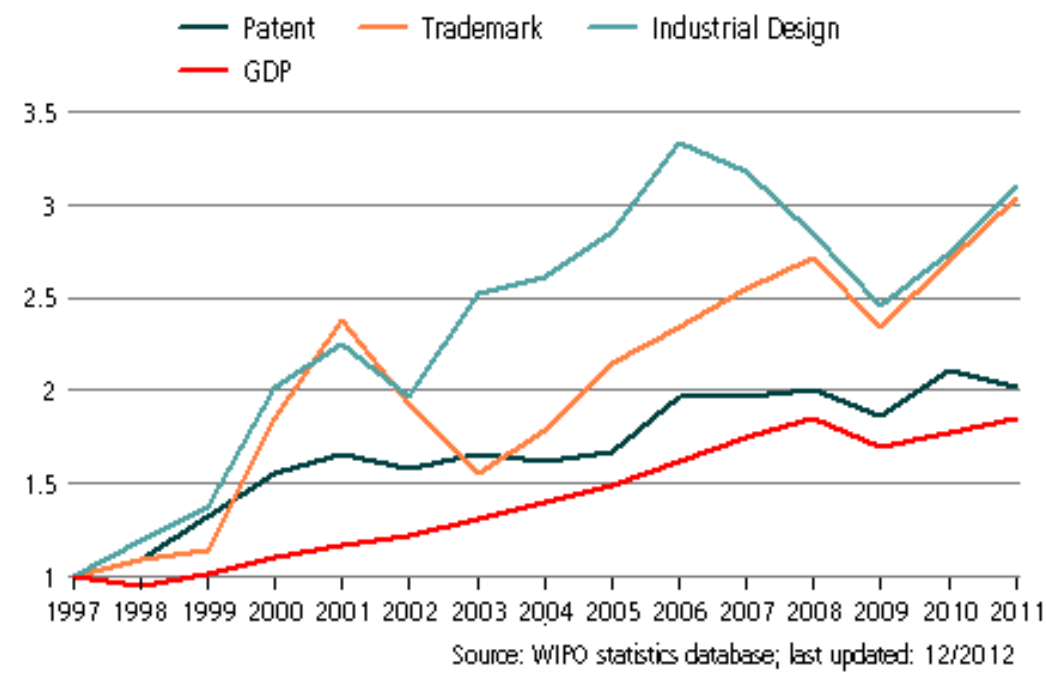

Fig. 1. GDP ratio, the number of applications for invention patents / trademarks / industrial designs in Russia [2].

IP Filings and Economic Growth (Set first available year to 1)

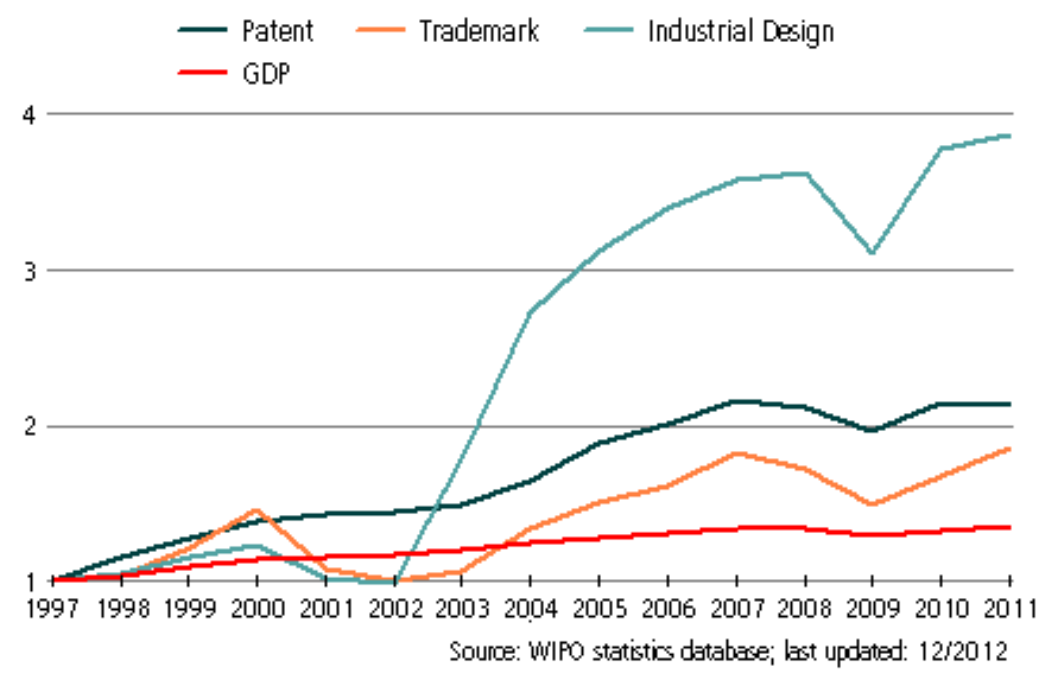

Fig. 2. GDP ratio, the number of applications for invention patents / trademarks / industrial designs in the US [2]. 
IP Filings and Economic Growth (Set first available year to 1)

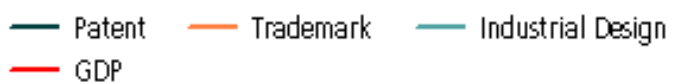

40

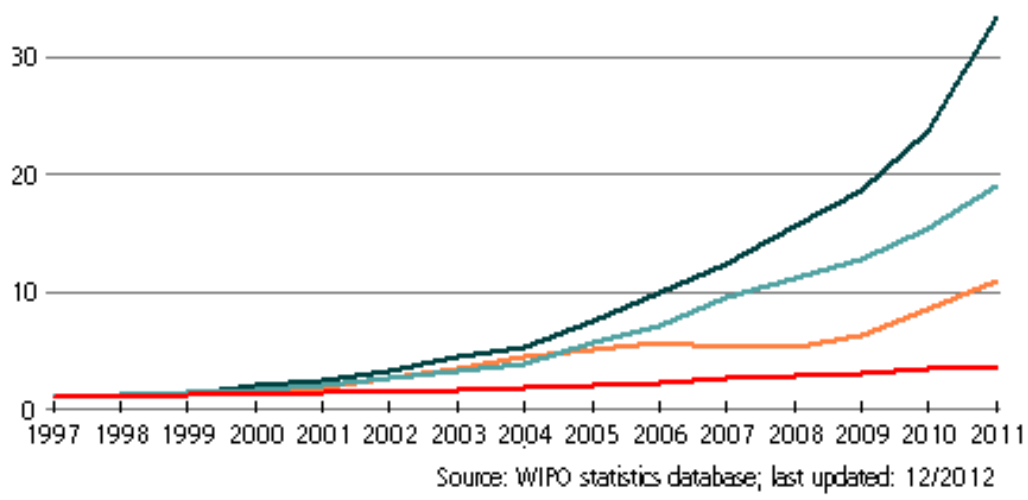

Fig. 3. GDP ratio, the number of applications for invention patents / trademarks / industrial designs in China [2].

\section{Methodology of the study}

The number of patents filling in the world in close to several hundred thousand with number of issued patents close to two hundred thousand each ear. The most challenging part is to create common ontology of the patent subject matter so it would be possible to relate patent data to the specific industries and skillsets. Another challenge was that there is no well-defined API neither for WPO nor for more commonly used Google Patent database.

The main goal of this study was to find if there is a correlation between world industry trends, Russian industry trends and the admission rate to the Russian universities. For this study we have selected two most dynamic in terms of patent filings industries - information technologies and biotechnologies. As a benchmark Russian university we have selected Lomonosov Moscow State University (MSU) which is according to the QS and THE world university ranking system is the best Russian university and one of the best universities in BRICs countries.

For the purpose of this study we have combined admission rates [6] at the government sponsored scholarships to departments of Mechanics and Mathematics, Applied Mathematics and Cybernetics and Physics as a benchmark for information technology and departments of Bioengineering and Bioinformatics, Biology, and Chemistry as a benchmark for biotechnologies.

For the patent data we used open OECD statistical databases [5] and we used only PCT issued patent data as it gives better representation of the real technological trends in the industry than national applications.

\section{Findings}

In this paper we will use described approach to consider date from OECD statistics database and correlate it to the official admission statistics of Lomonosov Moscow State University. We normalized all the data using data for 1999 as a reference. As we can see from the Figure 4 Russia and the rest of the world have significantly accelerated number of PCT filings while EU and USA filings are relatively flat. From this figure we can also see the tool which world economic crisis of 2001 and 2008 took on the number of PCT filings. What is interesting that admission rate to the ICT related departments of Lomonosov Moscow State University shows inverse correlation with economic crisis we can see that it picket around 2001 and 2008. It 
is also shows inverse correlation with the EU and the US patent trends demonstrating that Russian government doing a good job managing number of government scholarships in the ICT field and it could be related to the exponential grows of the Russian PCT filings.

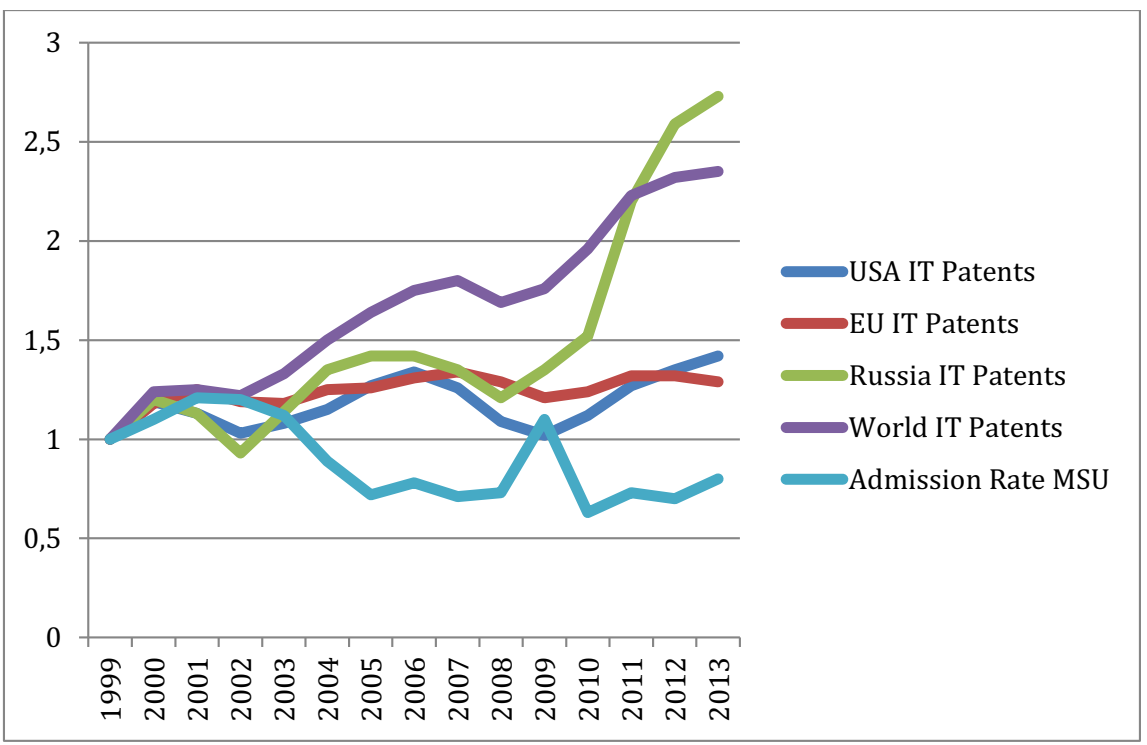

Fig. 4. Normalized number PCT (in the ICT related fields) patents filed by year and normalized admission rate to the corresponding departments of MSU.

We used the same approach to study correlation between the admission rate to the government-sponsored programs and technology trends in biotech field (Figure 5). As can be seen from the graph there is a correlation between number of Russian PCT filings in the biotech field and the admission rate. What is more interesting that we can see that spike in the admission rate flattered out and started to track average number of PCT patents around 2010. It could be attributed to better management of prospective students expectation or better management of government sponsored programs after the economic crisis of 2008-2009.

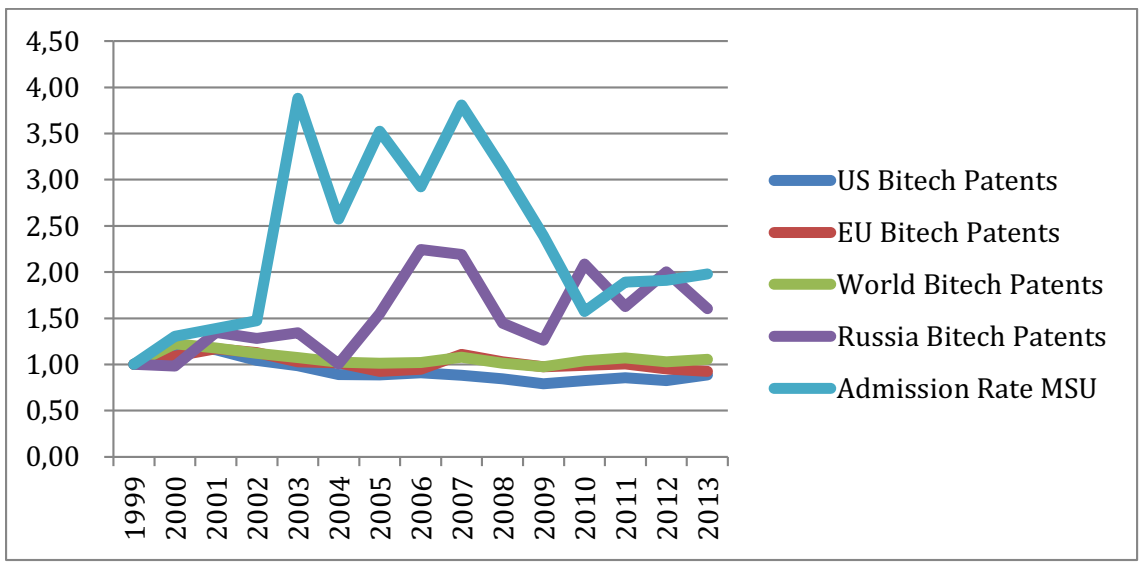

Fig. 5. Normalized number PCT (in the biotechnology related fields) patents filed by year and normalized admission rate to the corresponding departments of MSU. 


\section{Conclusions}

As we can see from the study there is a correlation between technological trends and the admission rate to the Russian government sponsored programs at Lomonosov Moscow State University both in ICT and biotechnological fields. Further study is required to find the reason why ICT field shows invers correlation while biotechnological field demonstrates a direct one. This study is important part of the treatment effect study of the government programs on innovation economy conducted by authors [7].

\section{References}

1. WPO statistics http://www.wipo.int/ipstats/en/statistics/country profile/

2. Science and Engineering Indicators 2012 Arlington, VA (NSB 12-01), January 2012 http://www.nsf.gov/statistics/seind12/c4/c4h.htm\#s2

3. Mary Ellen Mogee, Using Patent Data for Technology Analysis and Planning, Research-Technology Management Vol. 34 , Iss. 4,1991

4. US PTO IP Report March 2012 http://www.uspto.gov/news/publications/IP_Report_March_2012.pdf

5. OECD open access statistical data http://www.oecd.org/sti/inno/oecdpatentdatabases.htm

6. Lomonosov Moscow State University statistics http://www.msu.ru/entrance/concurs.html.

7. Igor Balk, Egor Mateshuk Cluster analysis of the bias in the SMB subsidy recipients selection 6th Seminar on Industrial Control Systems: analysis, modeling and computation Moscow February 2016 DOI: $10.1051 /$ itmconf/20160602002 